\title{
Planos de carreiras da rede estadual de ensino do Paraná e da rede municipal de ensino de Curitiba: um exercício comparativo
}

\author{
Ângelo Ricardo de Souza ${ }^{1}$ \\ angelosou@gmail.com \\ Andrea Barbosa Gouveia ${ }^{2}$ \\ andreabg@ufpr.br \\ Diana Cristina de Abreu ${ }^{3}$ \\ dianacristinaabreu@gmail.com \\ Gabriela Schneider ${ }^{4}$ \\ nupe@ufpr.br \\ Juliana Quaresma Gonçalves Ribeiro \\ nupe@ufpr.br
Marcelo Nogueira de Souza
nupe@ufpr.br

\section{Resumo}

Compreender as implicações das novas Diretrizes Nacionais da Carreira Docente para as condições de trabalho e valorização dos profissionais do

1 Doutorado em Educação pela Pontifícia Universidade Católica de São Paulo (2007)

Professor Adjunto da Universidade Federal do Paraná.

2 Doutorado em Educação pela Universidade de São Paulo (2008)

Professor adjunto da Universidade Federal do Paraná.

3 Doutoranda pela Universidade Federal do Paraná

4 Professora da educação básica

5 Aluna de IC Universidade Federal do Paraná

6 Mestrando pela Universidade Federal do Paraná 
magistério requer um conhecimento das dinâmicas locais de regulamentação de carreira, pois muitos estados e municípios aprovaram carreiras nos períodos anteriores e estas, certamente, têm identidades próprias que guardam proximidades e estranhamentos à legislação nacional recente. Assim, a proposta, neste artigo, é comparar duas carreiras em vigor no Estado do Paraná: uma, na Rede Municipal de Ensino de Curitiba, capital do estado, aprovada em 2001; e a outra, em vigor na Rede Estadual de Ensino do Estado do Paraná, aprovada em 2004. Analisam-se os elementos que definem tipo de admissão/ingresso e acesso à carreira; as formas de progressão/evolução e componentes complementares da remuneração. A análise evidencia certas garantias de qualidade para a carreira dos profissionais, ainda que bastante limitadas por condicionalidades orçamentárias das redes de ensino.

Palavras chave: Financiamento da Educação, Remuneração de professores, legislação.

\section{Introdução}

A discussão sobre carreira e remuneração docente no Brasil, ainda que estas sejam consideradas importantes instrumentos para a valorização do magistério, ganham visibilidade a partir do advento da Lei de Diretrizes e Bases da Educação Nacional - Lei n. 9.394/96 - (LDB). A LDB deixou a cargo dos vários sistemas de ensino a elaboração de políticas de valorização do magistério. Além disso, a questão da contratação e da normatização das condições de carreira do servidor público é uma competência exclusiva de cada ente federado.

Dessa forma, duas décadas após a aprovação da lei nacional, estudo de Balzano (2005) informa que a maioria dos estados brasileiros editou leis que regulamentaram a carreira e a remuneração docentes. Entretanto, nos 24 estados estudados pela autora, vários apresentaram dificuldades no atendimento de algumas diretrizes, principalmente aquelas que diziam respeito à instituição de incentivos de progressão por qualificação.

Em 1996, três meses antes da LDB, havia sido aprovada a Emenda Constitucional n. 14/96 instituindo o Fundo de Manutenção e 
Desenvolvimento do Ensino Fundamental e de Valorização do Magistério (Fundef) que, em princípio, visava à valorização do magistério nos estados e municípios. Diferentes autores analisam as positividades e negatividades dessa política de fundo no que concerne à remuneração docente. Sem dúvidas, o Fundef teve um caráter inédito na redistribuição de recursos entre os entes federados. O estabelecimento de não menos de $60 \%$ para valorização do magistério é destacado por Castro (1998) como um mérito da política de fundos. Já Davies (2001) concluiu que somente a redistribuição de recursos já existentes e destinados à educação não seria suficiente para a melhoria dos padrões educacionais, nem mesmo para a valorização do magistério.

Em seguida à aprovação do Fundef e da LDB, em 1997, o Ministério da Educação (MEC) e o Conselho Nacional de Educação (CNE) travaram um acirrado e importante debate sobre a elaboração das diretrizes nacionais para a carreira docente. Tal discussão envolveu polêmicas sobre o custoaluno e, especialmente, sobre o Piso Salarial Profissional Nacional. O resultado foi a Resolução CNE/CEB n. 03/97 que mais satisfez os interesses do governo, naquele período, do que os dos profissionais da educação.

As legislações citadas anteriormente disciplinaram a carreira docente no país até a aprovação da Emenda Constitucional n. 53, de 2006. Por meio dessa Emenda Constitucional, foram alterados os artigos 30, 206, 208, 211 e 212 da Constituição Federal. A alteração fez com que o artigo 206 passasse a ter uma redação que, além de contemplar a efetivação do Piso Salarial Profissional Nacional para os profissionais da educação escolar pública, definisse prazo para elaboração ou adequação de planos de carreira, no âmbito da União, dos Estados, do Distrito Federal e dos Municípios (BRASIL, 2006).

Por fim, em dezembro de 2006, foram sancionadas, pelo Presidente da República, a Lei n. 11.494/07 - que instituiu o Fundo de Manutenção e Desenvolvimento da Educação Básica e Valorização dos Profissionais da Educação (Fundeb) - que reafirma a necessidade de valorização dos profissionais de educação, e a Lei n. 11.738/07, que regulamentou o Piso Salarial Profissional Nacional para os Profissionais do Magistério 
Público da Educação Básica.

Com as alterações na política de financiamento pela instituição do Fundeb e pela sanção da Lei do Piso, as diretrizes para a carreira e remuneração docentes expostas na Resolução CNE/CEB n. 03/97 tornaram-se extemporâneas, havendo a necessidade da elaboração de novas diretrizes. Assim, por meio do Parecer CNE/CEB n. 9/09 e da Resolução CEB/CNE n. 02/09, foram fixadas as novas Diretrizes Nacionais para os Planos de Carreira e Remuneração do Magistério Público (DNC) nos estados, municípios e Distrito Federal.

Compreender as implicações das novas DNC para as condições de trabalho e valorização dos profissionais do magistério requer um conhecimento das dinâmicas locais de regulamentação de carreira, pois muitos estados e municípios aprovaram carreiras nos períodos anteriores. Estas, certamente, têm identidades próprias que guardam proximidades e estranhamentos à legislação nacional recente. Assim, o que se pretende neste artigo é comparar duas propostas de carreira em vigor: uma, na Rede Municipal de Ensino de Curitiba, capital do Estado do Paraná, aprovada em 2001; e a outra, em vigor na Rede Estadual de Ensino do Estado do Paraná, aprovada em 2004.

\section{Comparação dos planos de carreira da rede estadual do Paraná e da rede municipal de Curitiba}

Para a análise comparativa entre os sistemas de carreira da Rede Estadual de Ensino do Paraná (REE/PR) e da Rede Municipal de Ensino de Curitiba (RME/Curitiba), serão utilizados os Planos de Carreira, Cargos e Salários (PCCS) aprovados durante a primeira década dos anos 2000. No caso municipal, a lei que institui o plano é de 2001 e, no caso estadual, a lei foi aprovada em 2004. Consideram-se também, neste trabalho, as normatizações posteriores que alteraram os planos em questão.

Foram selecionadas, para a análise, três grandes categorias utilizadas no instrumento de coleta de dados elaborado no âmbito do Projeto de Pesquisa do Observatório da Educação (CAPES/INEP/SECAD), intitulado "Remuneração dos professores das escolas públicas da educação básica: configurações, impactos, impasses e perspectivas", 
quais sejam: 1. Tipo de admissão/ingresso e acesso; 2. Formas de progressão/evolução; 3. Componentes da remuneração. Tal seleção justifica-se no sentido de possibilitar uma visão ampla sobre a concepção de carreira em cada uma das redes e permitir algumas ponderações iniciais sobre as condições de trabalho propostas aos profissionais da educação.

\section{Tipo de admissão/ingresso e acesso}

A Constituição Federal de 1988 prevê que os ingressos para as carreiras de magistério público devam ser, obrigatoriamente, por concurso público de provas e títulos (BRASIL, 1988). Tal perspectiva é corroborada pelas DNC, conforme definição apresentada no QUADRO 1. As redes de Curitiba e do Paraná reafirmam esta prerrogativa.

\section{QUADRO 1}

Definição de Cargo e Carreira: Brasil, Paraná e Curitiba

\begin{tabular}{|c|c|c|}
\hline $\begin{array}{c}\text { Brasil/ Res. CNE/CEB n. } \\
\text { 02/2009 }\end{array}$ & Paraná/Lei n. 103/2004 & $\begin{array}{c}\text { Curitiba/Lei n. } \\
\text { 10.190/2001 }\end{array}$ \\
\hline $\begin{array}{l}\text { Art. } 4^{\circ} \text { As esferas da } \\
\text { administração pública que } \\
\text { oferecem alguma etapa da } \\
\text { Educação Básica, em quaisquer } \\
\text { de suas modalidades, devem } \\
\text { instituir planos de carreira para } \\
\text { todos os seus profissionais do } \\
\text { magistério, e, eventualmente, } \\
\text { aos demais profissionais } \\
\text { da educação, conforme } \\
\text { disposto no } \S 2^{\circ} \text { do artigo } 2^{\circ} \\
\text { desta Resolução, dentro dos } \\
\text { seguintes princípios: } \\
\text { I [...]. } \\
\text { II - acesso à carreira por } \\
\text { concurso público de provas } \\
\text { e títulos e orientado para } \\
\text { assegurar a qualidade da ação } \\
\text { educativa; }\end{array}$ & $\begin{array}{l}\text { Art. } 7^{\circ} \text { O cargo de Professor } \\
\text { da Rede Estadual de } \\
\text { Educação Básica do Paraná, } \\
\text { com descrição estabelecida } \\
\text { no Anexo II - Descrição } \\
\text { de Cargo, da presente Lei, } \\
\text { é acessível aos brasileiros } \\
\text { natos ou naturalizados, que } \\
\text { preencham os requisitos } \\
\text { estabelecidos em lei, com o } \\
\text { ingresso no Nível I, Classe } \\
\text { 1, da Carreira, mediante } \\
\text { concurso público de provas } \\
\text { e títulos. }\end{array}$ & $\begin{array}{l}\text { Art. } 9^{\circ} \text { A investidura } \\
\text { no cargo dar-se-á por } \\
\text { concurso público de } \\
\text { provas e títulos na parte } \\
\text { permanente, no nível } \\
\text { I, de acordo com a área } \\
\text { de atuação e habilitação } \\
\text { específica, conforme o } \\
\text { vencimento básico inicial } \\
\text { indicado para a parte } \\
\text { permanente na tabela, } \\
\text { constante do Anexo I, da } \\
\text { presente lei. }\end{array}$ \\
\hline
\end{tabular}

Fonte: BRASIL (2009); PARANÁ (2004); CURITIBA (2001). 
As diretrizes nacionais prevêem o concurso como condição de ingresso. Reforçam, também, o que é determinado no art. 85 da LDB, o qual dispõe que qualquer cidadão habilitado com a titulação própria poderá exigir a abertura de concurso público de provas e títulos, para cargo de docente de instituição pública de ensino que estiver sendo ocupado por professor não concursado, por mais de seis anos (BRASIL, 1996a).

A Rede Estadual de Ensino do Paraná, apesar de regulamentar, no Plano de Carreira, o ingresso por concurso público, contrata professores em Processo Seletivo Simplificado. Essa prerrogativa de contratação precária está prevista na Lei Complementar n. 108/05 (PARANÁ, 2005). Por meio dessa lei, o Estado do Paraná realiza contratação temporária para o provimento de diversos cargos de outras áreas e secretarias estaduais. Portanto, o vínculo temporário não é uma prerrogativa exclusiva dos trabalhadores em educação. No mês de outubro de 2010, 36\% dos professores e pedagogos em atividade na rede estadual estavam contratados pelo regime especial de trabalho, ou seja, não tinham as prerrogativas de um cargo investido por concurso público (TAB. 1).

\section{TABELA 1}

Professores em atividade na Rede Estadual de Ensino do Paraná, outubro de 2010

\begin{tabular}{ll|c|c}
\hline \multicolumn{1}{c|}{ TIPO DE VÍNCULO } & TOTAL & PERCENTUAL \\
\hline QPM-P & Professores do Quadro Próprio Magistério & 41.447 & 56,7 \\
QPM-E & Especialistas do Quadro Próprio Magistério & 4.769 & 6,5 \\
QUP & Professores do Quadro Único de Pessoal & 68 & 0,1 \\
TF57-L & Professor de 5/8 e 2 grau - lei n. 10.219/92 & 1 & 0,0 \\
PEPR & Professor contratados pelo & 1 & 0,0 \\
PEPE & PARANAEDUCACAO & 1 & 0,0 \\
REPR & PARANAEDUCACAO - pedagogos & 24.803 & 33,9 \\
REPE & Regime especial - professor & 2041 & 2,8 \\
TOTAL & Regime especial - pedagogo & 73.131 & 100 \\
\hline
\end{tabular}

Fonte: PARANÁ. Secretaria de Estado da Educação (2010).

O concurso público, no caso da RME/Curitiba, é a única forma de ingresso. Entretanto, é permitida a dobra de jornada, em Regime 
Integral de Trabalho (RIT). Esse vínculo é discriminado na Lei Municipal n. 8.248/93 e define que a dobra será devida quando os ocupantes da carreira do magistério optarem pela ampliação de jornada, ou seja, 40 horas semanais (CURITIBA, 1993). O RIT remunera o professor com um percentual de $100 \%$ sobre o valor do vencimento padrão percebido pelo mesmo e serve de base de cálculo para a contribuição previdenciária. Isto significa que o professor não dobra a sua própria remuneração, mas, ao ampliar a jornada, recebe a remuneração padrão básica do ponto onde está no quadro da carreira, sem eventuais gratificações. Dessa forma, de modo geral, não existem contratos precários na Rede Municipal de Curitiba, mas uma flexibilização dos contratos dos profissionais do quadro próprio do magistério.

Outro elemento interessante de ser contraposto, entre as legislações específicas de carreira, são as classificações dos cargos de ingresso que podem distinguir-se na nomenclatura e no significado. Nos casos aqui estudados, há uma coincidência de concepção, ainda que com diferenciação na nomenclatura: professor, no caso estadual, e profissional do magistério, no caso municipal. Nos dois casos, a compreensão do cargo inclui as atividades de docência e atividades de administração, planejamento e gestão, no mesmo sentido que as DNC de 2009 compreendem o trabalho docente:

São considerados profissionais do magistério aqueles que desempenham as atividades de docência ou as de suporte pedagógico à docência, isto é, direção ou administração, planejamento, inspeção, supervisão, orientação e coordenação educacionais, exercidas no âmbito das unidades escolares de Educação Básica, em suas diversas etapas e modalidades (Educação Infantil, Ensino Fundamental, Ensino Médio, Educação de Jovens e Adultos, Educação Especial, Educação Profissional, Educação Indígena), com a formação mínima determinada pela legislação federal de Diretrizes e Bases da Educação Nacional (BRASIL, 2009).

Ainda que as definições sejam semelhantes, há um modus operandi distinto nas redes. No caso da RME/Curitiba, todos os concursos são abertos para profissional do magistério e para ocupar as funções de 
"suporte técnico pedagógico" (CURITIBA, 2001) - os professores passam por um procedimento de mudança de área de atuação, interno à rede de ensino. No caso da REE/PR, os concursos são abertos para professor. Porém, já no concurso, há uma diferença entre professor docente e professor pedagogo. No caso da direção de escola, todos os profissionais do magistério das duas redes podem ocupar a função, por meio de processo eleitoral. Essas diferenças de procedimento parecem reter a mesma preocupação em garantir o enquadramento dos profissionais como professores, o que certamente tem relação direta com as condições especiais de aposentadoria previstas na legislação nacional.

\section{Formas de progressão/evolução na carreira}

Estudo de Morduchowicz (2003) sobre carreira de professores na América Latina evidencia que, "em geral, a carreira divide-se em níveis (entre quatro e sete) nos quais se avança de forma automática, ou pelo simples transcurso do tempo, ou por alguma combinação de fatores (antiguidade, capacitação, méritos, etc.) que gerem uma pontuação que habilite à promoção" (MORDUCHOWICZ, 2003, p. 18). Ainda que tais elementos possam ser motivo de discussão, são certamente características fundamentais para a compreensão de qualquer percurso do trabalhador, ao longo de uma carreira.

No caso do magistério, as DNC/09 definem, como elemento importante nos planos, a diferenciação dos "vencimentos ou salários iniciais da carreira dos profissionais da educação escolar básica" por meio do reconhecimento de diferenças de "titulação, entre os habilitados em nível médio e os habilitados em nível superior e pós-graduação lato sensu, e percentual compatível entre estes últimos e os detentores de cursos de mestrado e doutorado" (BRASIL, 2009). Observe-se que se trata de proposição acerca da evolução da remuneração ao longo da carreira e não uma discussão de atividades do trabalhador ao longo da carreira.

Os planos de carreira da REE/PR e RME/Curitiba conjugam elementos de progressão e evolução da remuneração ao longo das

7 Denominação para atividades do pedagogo escolar. 
carreiras. Essas progressões são baseadas na titulação, na formação continuada, no tempo de serviço e na avaliação de desempenho.

\subsection{Progressão/evolução na carreira baseada na formação acadêmica e na titulação}

As formas de progressão baseadas na formação acadêmica e na titulação são definidas nas redes, aqui em análise, conforme apresentado no QUADRO 2:

\section{QUADRO 2}

Definição de promoção na carreira por qualificação ou titulação:

Paraná, Curitiba.

\begin{tabular}{l|l}
\hline \multicolumn{1}{c|}{ Paraná/Lei n. 103/2004 } & \multicolumn{1}{|c}{ Curitiba/Lei n. 10.190/2001 } \\
\hline $\begin{array}{l}\text { Art. 11. A promoção na Carreira é a } \\
\text { passagem de um Nivel para outro, } \\
\text { mediante titulação acadêmica na }\end{array}$ & $\begin{array}{l}\text { Art. 14. O crescimento vertical } \\
\text { consiste na passagem de um nível } \\
\text { para outro superior, condicionado }\end{array}$ \\
$\begin{array}{l}\text { área da educação, nos termos de } \\
\text { resolução específica, ou Certificação } \\
\text { abtisponibilidade orçamentária e } \\
\text { abertura de Procedimento Seletivo }\end{array}$ \\
$\begin{array}{l}\text { Desenvolvimento Educacional - PDE, } \\
\text { previsto nesta Lei, com critérios e }\end{array}$ & $\begin{array}{l}\text { Específico pela Administração, de } \\
\text { acordo com a regulamentação da } \\
\text { presente lei. }\end{array}$ \\
\begin{tabular}{l} 
formas a serem definidos por lei. \\
\hline
\end{tabular}
\end{tabular}

Fonte: PARANÁ (2004); CURITIBA (2001), grifo nosso.

A primeira grande diferença entre as duas definições de progressão nos planos em análise está na compulsoriedade ou não do acesso ao mecanismo de progressão. No caso da REE/PR, a progressão é automática mediante apresentação do título, pelo professor, até o nível da especialização lato sensu. Depois, o acesso se dá por um processo de formação disciplinado pela Rede Estadual. Esse procedimento, denominado "Plano de Desenvolvimento da Educacional (PDE)", consiste em um programa de formação, em parceria com Instituições

8 O PDE, integrado às atividades da formação continuada em Educação, disciplina a promoção do professor para o Nível III da Carreira, conforme previsto no PCCS Estadual. Sua regulamentação se deu através da Lei Complementar n. 130 de 2009. Segundo a Secretaria de Educação do Estado do Paraná, o objetivo do programa é proporcionar aos professores da rede pública estadual subsídios 
de Ensino Superior públicas do Estado, com dois anos de duração, em que o professor realiza estudos e um projeto de intervenção em escolas.

Para os professores da RME/Curitiba, as progressões pela titulação sofreram mudanças desde a aprovação do plano de carreira, em 2001. A carreira do magistério está dividida em parte especial, que contempla professores com habilitação em nível médio, e uma parte permanente. Essa segunda parte é dividida, atualmente, em quatro níveis: licenciatura plena, especialização, mestrado e doutorado.

O QUADRO 3 apresenta uma síntese do movimento previsto nas carreiras nas duas redes:

\section{QUADRO 3}

Progressão por qualificação ou titulação: Paraná, Curitiba.

\begin{tabular}{|c|c|c|c|c|c|}
\hline \multicolumn{3}{|c|}{ Paraná/Lei n. 103/2004 } & \multicolumn{3}{|c|}{ Curitiba/Lei n. 10.190/2001 } \\
\hline Nome & $\begin{array}{c}\text { Formação } \\
\text { exigida }\end{array}$ & $\begin{array}{c}\text { Diferencial } \\
\text { remuneração }\end{array}$ & Nome & $\begin{array}{c}\text { Formação } \\
\text { exigida }\end{array}$ & $\begin{array}{c}\text { Diferencial } \\
\text { remuneração }\end{array}$ \\
\hline $\begin{array}{c}\text { Especial } \\
1\end{array}$ & $\begin{array}{c}\text { Nivel médio na } \\
\text { modalidade } \\
\text { normal }\end{array}$ & $70 \%$ do nível 1 & Parte especial & Magistério & $85 \%$ do nível 1 \\
\hline $\begin{array}{c}\text { Especial } \\
2\end{array}$ & $\begin{array}{c}\text { Licenciatura } \\
\text { curta }\end{array}$ & $75 \%$ do nível 1 & & & \\
\hline $\begin{array}{c}\text { Especial } \\
3\end{array}$ & $\begin{array}{c}\text { Licenciatura } \\
\text { curta com } \\
\text { estudos } \\
\text { adicionais } \\
\end{array}$ & $85 \%$ do nível 1 & $\begin{array}{c}\text { Parte } \\
\text { permanente/ } \\
\text { Nivel } 1\end{array}$ & $\begin{array}{c}\text { Graduação em } \\
\text { licenciatura }\end{array}$ & $100 \%$ \\
\hline Nivel 1 & $\begin{array}{c}\text { Graduação em } \\
\text { licenciatura }\end{array}$ & $100 \%$ & $\begin{array}{c}\text { Parte } \\
\text { permanente/ } \\
\text { Nivel } 2\end{array}$ & Especialização & $\begin{array}{l}15 \% \text { a mais } \\
\text { que o nível } 1\end{array}$ \\
\hline Nivel 2 & Especialização & $\begin{array}{c}25 \% \text { a mais } \\
\text { que o nível } 1\end{array}$ & $\begin{array}{c}\text { Parte } \\
\text { permanente/ } \\
\text { Nivel } 3\end{array}$ & Mestrado & $\begin{array}{c}15 \% \text { a mais } \\
\text { que o nível } 2\end{array}$ \\
\hline Nivel 3 & PDE & $\begin{array}{c}5 \% \text { a mais que } \\
\text { o nivel } 2\end{array}$ & $\begin{array}{c}\text { Parte } \\
\text { permanente/ } \\
\text { Nivel } 4\end{array}$ & Doutorado & $\begin{array}{c}15 \% \text { a mais } \\
\text { que o nível } 3\end{array}$ \\
\hline
\end{tabular}

Fonte: PARANÁ (2004); CURITIBA (2001).

A formação mínima exigida para ingresso na carreira docente pública municipal, em Curitiba, é a graduação em curso de licenciatura. Os professores que já estavam em atividade e que tinham como título

teórico-metodológicos para o desenvolvimento de ações educacionais sistematizadas e que resultem em redimensionamento de sua prática. Para desenvolver o PDE, os professores o fazem com afastamento remunerado de $100 \%$ de sua carga horária efetiva no primeiro ano e de $25 \%$ no segundo ano do Programa. O PDE também possibilita o aproveitamento da titulação dos cursos de mestrado e/ou doutorado: os professores com esses títulos passam pelo processo seletivo, devem obedecer todos os critérios do programa e, assim, os títulos serão aproveitados para a obtenção da certificação do PDE. 
o magistério de nível médio/curso normal de nível médio foram enquadrados na parte especial do plano que está em extinção. Assim, a partir de 2001, o graduado, ao ingressar na RME/Curitiba, o faz no nível I. Na verdade, independentemente da formação, todos ingressam no nível I por pelo menos três anos, que é o tempo de estágio probatório. Assim, o ingressante que tiver especialização lato sensu concorre à qualificação de nível II, logo que complete os três anos de estágio probatório.

O PCCS previa que até o ano de 2003 a administração realizasse o procedimento de forma escalonada, garantindo 800 vagas para que os profissionais do magistério, devidamente habilitados, pudessem realizar a migração do nível I para o nível II da tabela. Após 2003, o município passaria a assegurar, no mínimo, 100 (cem) vagas por procedimento. Para a realização de cada procedimento, a administração fixa o número de vagas, em tópico específico de lei orçamentária. Ou seja, diferentemente da rede estadual, esse procedimento não é automático, alguns conseguem avançar e outros não.

Nos anos de 2004 e 2005, foram destinadas, pela administração, 400 vagas em cada procedimento. Em 2006, o número passou para 800 vagas para o nível II e 60 para o nível III Em 2007, novamente, 800 para o nível II e 30 para o nível III. Mesmo com o aumento do numero de vagas, muitos profissionais do magistério não são enquadrados pela sua maior habilitação.

Até 2005, o crescimento vertical acontecia por meio de um processo seletivo, em forma de prova de conhecimentos. Como existe um número reduzido de oferta de vagas, os profissionais concorriam entre si disputando-as. A prova para a promoção no sistema vertical era a mesma para todos os candidatos; entretanto, as especializações eram nas mais diferentes áreas da educação. $\mathrm{O}$ argumento, defendido pela administração municipal, era de que, como muitas especializações não apresentavam qualidade, era preciso selecionar os candidatos mediante prova de conhecimentos.

No ano de 2005, a prova deixou de ocorrer e foi substituída por outros critérios, como tempo de serviço, tempo de titulação na pós-graduação e publicações de textos científicos, permanecendo a reivindicação do 
sindicato municipal pelo pagamento pela maior habilitação, ou seja, crescimento vertical automático mediante a apresentação da titulação. Os últimos procedimentos, apesar de ampliarem o número de vagas previsto inicialmente na legislação, continuam definindo isto via Decretos; portanto, mantém-se a concepção de seleção entre os profissionais e uma articulação, para as progressões, com a disponibilidade orçamentária do município.

Em 2007, a ação do Sindicato do Magistério Municipal de Curitiba resultou na aprovação de mais um nível na carreira: o doutorado. Esse nível, regulamentado no art. $2^{\circ}$ da Lei n. 12.348 , foi tratado de forma diferente: aos profissionais já enquadrados no nível III, para o qual se exige formação de mestrado e que passaram pelo procedimento seletivo para tanto, são, a partir dali, enquadrados de forma automática no último nível da carreira. Certamente não há razão para alegar que é preciso submeter os profissionais da educação que têm doutorado reconhecido nacionalmente na área a novos procedimentos avaliativos. Portanto, é um avanço o procedimento ser automático para esse nível. Pode-se perguntar por que não usar o mesmo critério para os mestres em educação. Isto parece reforçar a explicação de que os procedimentos seletivos têm conotação muito mais orçamentária, já que o número de doutores nas redes públicas de ensino básico, e em Curitiba isto não é diferente, é bastante reduzido.

Na comparação entre os dois planos de carreira, percebe-se que, no caso da rede estadual, ao menos até o nível II, a progressão é automática e, na rede municipal, condicionada a um número de vagas definidas anualmente. Outra diferença está no fato de que na REE/PR não estão contemplados os títulos de mestre e doutor, já contemplados na RME/ Curitiba em consonância com as diretrizes nacionais e a mobilização local.

Em ambos os planos, a condição de ingresso tem sido a licenciatura plena. Portanto, as chamadas "partes especiais dos planos" estão em extinção progressiva, ou seja, não ocorre ingresso de novos professores nesses níveis. Entretanto, os professores que lá se encontravam na aprovação dos planos de carreiras poderão progredir no mesmo nível e, também, ao concluírem a graduação, poderão passar para a parte permanente do plano e ter, ao longo do tempo, os benefícios salariais das 
progressões. Os professores contratados temporariamente, no caso da REE/ PR denominados professores PSS, não têm direito aos benefícios da carreira.

\subsection{Progressão/evolução baseada na formação continuada e na avaliação de desempenho}

Segundo as diretrizes nacionais para a carreira docente, a formação continuada e a avaliação de desempenho são elementos que podem constituir-se em incentivos de progressão salarial. Esses elementos estão presentes nos PCCS das duas redes de ensino aqui analisadas.

Na REE/PR, o procedimento que incentiva a formação continuada, com aumento do vencimento do professor, é chamado de progressão. No caso da RME/Curitiba, é chamado de crescimento horizontal. Ambos definem tal procedimento como aquele que ocorre dentro do mesmo nível da carreira. Ou seja, os professores avançam em classes, na tabela de vencimentos da $\mathrm{REE} / \mathrm{PR}$, e em referências, na tabela salarial na RME/Curitiba.

Na rede estadual, a tabela de vencimentos é composta de 11 classes, em cada nível. As exigências para avançar são a avaliação de desempenho e a qualificação profissional e os avanços ocorrem a cada dois anos para os professores. Em um mesmo nível, há uma diferença percentual de $5 \%$ entre uma classe e outra. A TAB. 2 apresenta a remuneração para o Quadro Próprio do Magistério, no ano de 2010, considerando os efeitos da progressão:

\section{TABELA 2}

Tabela de Vencimento Básico e Remuneração da Carreira Quadro Próprio do Magistério da REE/PR, 20 horas semanais, 2010

\begin{tabular}{l|c|c|c|c|c|c|c|c|c|c|c}
\hline NíVEIS & \multicolumn{10}{|c}{ CLASSES } \\
\hline & 1 & 2 & 3 & 4 & 5 & 6 & 7 & 8 & 9 & 10 & 11 \\
Especial 1 & 542 & 569 & 597 & 627 & 659 & 692 & 726 & 763 & 801 & 841 & 883 \\
Especial 2 & 581 & 610 & 640 & 672 & 706 & 741 & 778 & 817 & 858 & 901 & 946 \\
Especial 3 & 658 & 691 & 726 & 762 & 800 & 840 & 882 & 926 & 973 & 1021 & 1072 \\
Nível 1 & 774 & 813 & 854 & 896 & 941 & 988 & 1038 & 1090 & 1144 & 1202 & 1262 \\
Nível 2 & 968 & 1016 & 1067 & 1121 & 1177 & 1236 & 1297 & 1362 & 1431 & 1502 & 1577 \\
Nível 3 & 1656 & 1739 & 1826 & 1917 & 2013 & 2114 & 2219 & 2330 & 2447 & 2569 & 2668 \\
\hline
\end{tabular}

Fonte: PARANÁ (2010).

Nota: Valores em Reais (R\$). 
Para a progressão, os professores da rede estadual precisam compor os resultados de um processo de avaliação de desempenho e de formação continuada. Dessa forma, a cada interstício de dois anos, são computados até 15 pontos para avaliação de desempenho e até 30 pontos para atividades de formação e/ou qualificação profissional. A cada 15 pontos acumulados, o professor terá garantida a progressão equivalente a uma classe, podendo avançar até três classes na carreira, em cada progressão.

Para conhecer o tempo que o profissional leva para atingir o final da carreira, no caso da REE/PR, devemos considerar que essa carreira tem uma especificidade, ou seja, até a classe 11 do nível II a progressão é automática. A partir daí ela está condicionada à aprovação no PDE que oferece um número limitado de vagas. Assim, para progredir do nível I classe 1 até o nível II classe 11 o professor da rede estadual poderá chegar ao final da carreira em aproximadamente 15 anos. Para aqueles que são selecionados no PDE, serão, no máximo, mais 15 anos para chegar ao final da carreira. Dessa forma, fazendo as ponderações, aos que não forem contemplados no PDE, a previsão de final de carreira será em 15 anos e, aos contemplados pelo PDE, aproximadamente 30 anos.

No caso de Curitiba, a tabela de vencimentos estrutura-se em 44 referências em cada nível da parte permanente do plano, conforme distribuição apresentada no QUADRO 3. O crescimento horizontal, ou a passagem de uma referência para outra, no mesmo nível, ocorre a cada dois anos. Na rede municipal, o professor avança somente uma referência por procedimento e recebe um acréscimo no salário de $2,8 \%$ (TAB. 3 ): 


\section{TABELA 3}

Tabela de Vencimento Básico e Remuneração da Carreira Quadro Próprio do Magistério da RME/Curitiba, 20 horas semanais, 2010

\begin{tabular}{l|c|c|c|c|c|c|c|c|c|c}
\hline NÍVEIS & \multicolumn{10}{|c}{ REFERÊNCIAS } \\
\hline Parte especial & Código & $\mathrm{A}$ & $\mathrm{B}$ & $\mathrm{C}$ & $\mathrm{D}$ & $\mathrm{E}$ & $\mathrm{F}$ & $\mathrm{G}$ & $\mathrm{H}$ & $\mathrm{I}$ \\
& 100 & 743 & 764 & 785 & 807 & 830 & 853 & 877 & 901 & 927 \\
& 101 & 953 & 979 & 1007 & 1035 & 1064 & 1094 & 1124 & 11560 & 1188 \\
& 102 & 1221 & 1256 & 1291 & 1327 & 1364 & 1402 & 1442 & 1482 & 1524 \\
\hline Parte & 103 & & & & & & & 1008 & 1037 & 1066 \\
permanente/ & 104 & 1096 & 1126 & 1158 & 1190 & 1224 & 1258 & 1293 & 1329 & 1366 \\
Nível 1 & 105 & 1405 & 1444 & 1485 & 1526 & 1569 & 1613 & 1658 & 1704 & 1752 \\
& 106 & 1801 & 1852 & 1904 & 1957 & 2012 & 2068 & 2126 & 2186 & 2247 \\
& $107-\mathrm{PI}$ & 2310 & 2374 & 2441 & 2509 & 2579 & 2652 & 2726 & 2802 & 2881 \\
& $108-\mathrm{PI}$ & 2961 & 3044 & 3130 & 3217 & 3307 & 3400 & 3495 & 3593 & 3691 \\
\hline Parte & 107 & 983 & 1010 & 1038 & 1067 & 1097 & 1128 & 1160 & 1192 & 1226 \\
permanente/ & 108 & 1260 & 1295 & 1331 & 1369 & 1407 & 1447 & 1487 & 1529 & 1572 \\
Nível 2 & 109 & 1616 & 1661 & 1707 & 1755 & 1804 & 1855 & 1907 & 1960 & 2015 \\
& 110 & 2072 & 2130 & 2189 & 2250 & 2314 & 2378 & 2445 & 2513 & 2584 \\
& $111-P I I$ & 2656 & 2731 & 2807 & 2886 & 2966 & 3049 & 3135 & 3223 & 3313 \\
& $112-\mathrm{PII}$ & 3406 & 3501 & 3599 & 3700 & 3804 & 3910 & 4020 & 4132 & 4248 \\
\hline Parte & 111 & 1130 & 11622 & 1194 & 1228 & 1262 & 1297 & 1334 & 1371 & 1410 \\
permanente/ & 112 & 1449 & 1490 & 1531 & 1574 & 1618 & 1664 & 1710 & 1758 & 1807 \\
Nível 3 & 113 & 1858 & 1910 & 1963 & 2018 & 2075 & 2133 & 2193 & 2254 & 2317 \\
& 114 & 2382 & 2449 & 2518 & 2588 & 2661 & 2735 & 2812 & 2891 & 2971 \\
Parte & $115-\mathrm{PIII}$ & 3055 & 3140 & 3228 & 3319 & 3411 & 3507 & 3605 & 3706 & 3810 \\
Nível 4 & $116-\mathrm{PIII}$ & 3917 & 4026 & 4139 & 4255 & 4374 & 4497 & 4623 & 4752 & 4885 \\
\hline & 500 & 1300 & 1336 & 1373 & 1412 & 1451 & 1492 & 1534 & 1577 & 1621 \\
& 501 & 1666 & 1713 & 1761 & 1810 & 1861 & 1913 & 1967 & 2022 & 2078 \\
& 502 & 2137 & 2197 & 2258 & 2321 & 2386 & 2453 & 2522 & 2592 & 2665 \\
& 503 & 2740 & 2816 & 2895 & 2976 & 3060 & 3145 & 3233 & 3324 & 3417 \\
& 504 & 3513 & 3611 & 3712 & 3816 & 3923 & 4033 & 4146 & 4262 & 4318 \\
& 505 & 4504 & 4630 & 4760 & 4893 & 5030 & 5171 & 5316 & 5465 & 5618 \\
\hline
\end{tabular}

Fonte: CURITIBA (2010).

Nota: Valores em Reais (R\$).

Os professores que participam do processo preenchem um formulário de gestão profissional que considera as atividades realizadas na RME/ Curitiba nos últimos 24 meses (no máximo), atribuindo peso diferente para a atuação em unidades escolares e outras atividades: professores em atividades nas unidades escolares de ensino fundamental ou educação infantil recebem peso 3 na avaliação; profissionais em atividades de 
docência em outras instituições ${ }^{9}$, no período, recebem peso 2,5 na avaliação.

Também são considerados a formação continuada, cursos, autoria e co-autoria em livros e artigos, participação em palestras e eventos, outra graduação, a carga horária de cursos de pós-graduação, participação em bancas de concurso público e em órgãos colegiados (Conselhos e Associações de Pais e Professores), cursos de aprimoramento em informática e idiomas, todos eles com pontuação diferente, definida em formulário de gestão profissional.

Apesar de a lei municipal estabelecer que apenas $80 \%$ dos profissionais serão contemplados com o crescimento horizontal, anualmente, somente os professores com estabilidade participam dos procedimentos. Isto tem feito com que todos os que participam sejam contemplados, uma vez que os professores em estágio probatório não concorrem.

Há uma pontuação mínima necessária para o crescimento. Quanto a esse critério cabem algumas ponderações: a) somente por estar atuando na rede ou em escola (72 pontos) ou em outros órgãos (60 pontos) o professor já faz grande parte da pontuação necessária ao avanço; b) como os professores podem utilizar certificados de atividades anteriores ao período do crescimento e equivalentes a até 10 anos de atividades, o crescimento acaba por não contemplar a formação continuada efetivamente realizada no período; c) em cada procedimento, é possível o avanço de apenas uma referência, ou seja, não há estímulo para que os professores façam mais formação; d) somente avançam mais de uma referência os professores com títulos de mestre (duas referências) e doutores (três referências) em apenas uma progressão.

Considerando a atual estrutura de crescimento horizontal na qual existem 44 referências, para um professor que faça todos os procedimentos (no interstício de dois anos), descontando o estágio probatório, serão necessários 89 anos para se chegar ao fim da carreira. Ou seja, diferentemente da tabela salarial da rede estadual, aqui o tempo para chegar ao final da carreira é inviável.

9 Os profissionais do magistério podem estar atuando: a) Na sede da Secretaria Municipal de Educação (SME), nos Núcleos Regionais de Ensino, nos Centros Municipais de Atendimento Especializado. b) Na Secretaria de Esporte e Lazer. c) Por força de Convênio de Cooperação Técnica, com a REE/PR ou com outras entidades conveniadas, exclusivamente para programas de escolarização e apoio à escolarização.

d) Em função de apoio no Farol do Saber localizado na praça. 


\section{Componentes da remuneração docente}

As condições de remuneração dos profissionais da educação têm sido identificadas na literatura como um dos elementos de baixa atratividade da profissão (PINTO, 2007). Entre os elementos que justificam as condições de remuneração, no âmbito da economia, estão condições de oferta e demanda entre mão-de-obra e emprego (BECKER, 2008) que, no caso dos professores, têm relação entre a oferta de vagas no sistema educacional e os profissionais necessários para garantir o atendimento dos alunos. Dada a dimensão do sistema educacional brasileiro e a necessária limitação do número de alunos por professor, pode-se concordar com Barros et al.:

Poucos bens ou serviços são tão intensivos em mão-de-obra, na sua produção, como os serviços educacionais, levando a que quase $70 \%$ dos custos neste setor sejam despesas com a remuneração do trabalho. Além disso, a produção desses bens é percebida como muito sensível à qualidade da mão-de-obra utilizada, embora a magnitude desta sensibilidade seja um tema ainda controverso. Estas duas características tornam a questão da adequada remuneração da mão-de-obra na produção deste serviço de vital importância. Devido a estas características, salários ligeiramente acima do mercado representam acréscimos significativos no custo de produção. Estes aumentos ocasionam uma elevação no valor das mensalidades, no caso da educação privada; ou um maior gasto público, no caso das escolas públicas. Ao contrário, salários inferiores aos do mercado reduzem a atratividade da profissão afastando os trabalhadores com maior potencial, estimulando a rotatividade e, portanto, levando a uma perda de qualidade e de produtividade da mãode-obra. (BARROS et al., 2001, p. 4)

A literatura sobre remuneração de professores, no âmbito da economia (BECKER, 2008; BARROS et al., 2008; ANUATTI et al., 2004), tem se dedicado a propor formas de mensurar ganhos adicionais que o Setor Público permita aos profissionais, de forma a argumentar que os salários não são tão mais baixos que os do mercado privado, 
considerando as vantagens incorporadas aos salários. Há metodologias muito polêmicas nessa questão, pois, considerando as condições, por exemplo, de qualidade de vida atual dos profissionais, exercícios como os de ganhos com aposentadoria futura são bastante abstratos para garantir a manutenção de bons profissionais no exercício da docência.

Não é possível, neste artigo, considerar todos esses elementos, pois interessa-nos aqui quais elementos compõem a remuneração de professores a partir das definições dos dois planos de carreira. Entretanto, cabe essa pequena digressão, pois, quando se comparam condições de remuneração entre os profissionais da educação, é importante diferenciar vencimento básico (aquele previsto nas tabelas salariais apresentadas para cada uma das redes) do total da remuneração. $\mathrm{O}$ total da remuneração inclui gratificações e adicionais que podem ser transitórios ou permanentes, a depender de regulamentação específica.

Assim, para compreender as condições de valorização da profissão docente nas redes de Curitiba e do estado do Paraná, cabe considerar quais elementos, além do vencimento básico por titulação e progressão, podem ser acrescidos aos pagamentos de professores.

As carreiras analisadas na pesquisa em questão apresentam como primeiro componente para a evolução salarial dos profissionais do magistério os adicionais de tempo de serviço, conforme previsto nas DNC/2009. Na Rede Municipal de Ensino, o adicional de tempo de serviço foi instituído em 1985, pela Lei Municipal n. 6.761/85, e não foi revogado no âmbito do PCCS. Essa lei define que os profissionais do magistério farão jus aos seguintes percentuais de gratificação:

I - Quando do sexo masculino, à base de cinco por cento $(5 \%)$ por qüinqüênio, até completar trinta (30) anos de serviço, num total de trinta por cento $(30 \%)$ e de cinco por centro $(5 \%)$ por ano excedente, até atingir o máximo de cinqüenta por cento (50\%). II - Quando do sexo feminino, à base de cinco por cento $(5 \%)$ por qüinqüênio, até completar vinte e cinco anos de serviço, num total de vinte e cinco por cento $(25 \%)$, e de cinco por cento $(5 \%)$ por ano excedente, até atingir o máximo de cinqüenta por cento (50\%) (CURITIBA, 1985). 
Observe-se que esta forma da gratificação insere um incentivo à permanência dos profissionais na ativa, mesmo após completar o tempo de aposentadoria. Isto tem um elemento positivo de valorização da experiência. Entretanto, tem implicações no desgaste do profissional e uma relação contraditória, uma vez que se tem a compreensão de que a aposentadoria especial justifica-se, no caso dos professores, devido às especificidades do trabalho docente.

O adicional por tempo de serviço também é praticado na REE/PR. A legislação que especifica o incentivo remuneratório é a Lei Complementar n. 103/04. O sentido é o mesmo que o encontrado no caso anterior. Os professores fazem jus a um percentual de $5 \%$ de acréscimo ao valor correspondente ao nível/classe em que se encontram na carreira, a cada cinco anos. Após completado o tempo mínimo de aposentadoria, os professores fazem jus a um incremento anual de $5 \%$, até o teto de $50 \%$ de gratificação (PARANÁ, 2004).

Portanto, ambas as redes possuem, como um dos componentes da remuneração, o adicional de tempo de serviço, o que é uma característica presente na maioria dos planos de carreira, inclusive da América Latina (TORRECILA, 2006). Ao contemplar o tempo de serviço para a progressão salarial dos profissionais do magistério, os planos de carreiras expressam um importante indicador para a valorização da carreira docente. Entretanto, esse indicador não poderá ser o único, pois somente o tempo de serviço ou a experiência profissional podem não garantir qualidade para o processo pedagógico. Por isso, a esse instrumento de progressão, devem estar associados outros indicadores como a titulação acadêmica, o aperfeiçoamento profissional, etc. No caso das redes aqui em discussão, os procedimentos anteriores de progressão parecem garantir uma articulação melhor entre tempo de serviço e qualificação, seja na formação inicial ou na formação continuada dos professores.

Um segundo elemento de composição da remuneração docente, presente nas duas redes, é o adicional noturno. Diferente do tempo de serviço, por razões evidentes, esse adicional é específico para os profissionais que atuam no período noturno.

No caso da REE/PR, o adicional é de $20 \%$ sobre o valor correspondente 
ao nível e à classe em que o professor está na carreira, segundo a carga horária, para o exercício do trabalho a partir das 18 horas. No caso da RME/Curitiba, o adicional noturno também está previsto desde o Estatuto do Magistério (Lei n. 6.761/85), anterior ao PCCS. Contudo, todas as unidades da Rede Municipal de Ensino encerram suas atividades antes das $22 \mathrm{~h}$. Assim, mesmo sendo previsto em lei, os professores que trabalham com a Educação de Jovens e Adultos (EJA), ainda que no período noturno, não recebem o adicional.

Um terceiro elemento que pode compor a remuneração é o auxílio transporte. As redes analisadas apresentam formas diferenciadas na concessão do auxílio transporte. Na RME/Curitiba, o auxílio é pago em pecúnia havendo um escalonamento do desconto do auxílio transporte de $1 \%, 3 \%$ e $6 \%$, de acordo com a faixa salarial do servidor. Mas existe um teto para o recebimento do auxílio transporte que está disciplinado na Lei Orgânica Municipal e pelo Decreto n. 507/96. A existência do teto para o recebimento do auxílio transporte representa uma problemática, pois quando o servidor, por mérito, alcança uma determinada faixa salarial, o pagamento do auxílio é retirado e esse servidor passa a ter comprometida parte da sua remuneração com o deslocamento casa-trabalho-casa.

Na REE/PR, o auxílio transporte foi definido, no plano de carreira, a partir de um valor fixo correspondente a um percentual sobre um nível da carreira. Os professores em exercício nos estabelecimentos de ensino, Núcleos Regionais da Educação, Secretaria de Estado da Educação e unidades a ela vinculadas recebem auxílio transporte correspondente, no mínimo, a $24 \%$ sobre o vencimento do nível I, classe 5, da carreira, com incidência proporcional à jornada de trabalho de 20 horas semanais (PARANÁ, 2004). Não está previsto um teto para o recebimento do auxílio e o recebimento também não está articulado à apresentação de comprovante de residência para efeito de verificação do trajeto percorrido pelo servidor.

O quarto elemento de composição da remuneração, identificado nos planos de carreira, é o abono permanência. A Emenda Constitucional n. 41/03 criou o abono permanência que consiste no recebimento do correspondente ao "valor da sua contribuição previdenciária" (BRASIL 2003). Na prática, o servidor que completou o tempo de aposentadoria 
deixa de fazer sua contribuição previdenciária de $11 \%$. Portanto, tem esse valor acrescido à sua remuneração. Por força da lei federal, tal mecanismo aparece nas duas redes de ensino analisadas.

O quinto elemento de remuneração identificado no PCCS, mas apenas na RME/Curitiba, tem relação com alguma forma de incremento na qualidade de ensino oferecida aos estudantes. Tratase de uma gratificação de difícil provimento ou difícil acesso. Essa gratificação é um incentivo pago aos professores para sua fixação em unidades educacionais consideradas de difícil provimento. Alguns estabelecimentos da rede municipal de ensino são considerados assim. $\mathrm{O}$ que determina se uma escola tem essa característica é a sua dificuldade de lotação, ou seja, o quão difícil é ter seu quadro de vagas preenchido no início do ano letivo. Além da lotação, a distância do marco zero da cidade, a alta rotatividade de profissionais a cada ano letivo e as condições de vulnerabilidade social da comunidade são critérios considerados.

Em 2001, o PCCS estabeleceu que os profissionais do magistério lotados nas escolas consideradas de difícil provimento, na rede municipal de Curitiba, receberiam $10 \%$ sobre o vencimento inicial da carreira, em forma de adicional de difícil provimento. Nos anos posteriores à lei, os decretos que definem quais são as unidades de difícil provimento são publicados antes do edital que estabelece o processo de remanejamento ${ }^{10}$. Os profissionais do magistério, à medida que identificam unidades com os mesmo problemas de lotação, têm reivindicado a extensão da gratificação.

Embora tal adicional seja potencialmente um indicativo de qualidade para a oferta de escolas e para a carreira dos profissionais, a forma como a administração municipal realiza o pagamento da gratificação gera alguns questionamentos.

O regime de previdência dos servidores públicos municipais é contributivo, na forma do artigo 40 da Constituição Federal. Nesse regime, apenas são incorporáveis aos proventos de aposentadoria e pensões aquelas verbas sobre as quais tenha incidido a contribuição

11 Segundo a Portaria n. 25/2007, o Remanejamento é a concessão de transferência do exercício do Profissional do Magistério e/ ou integrante de outro quadro profissional lotado na SME de determinada unidade para outra, seja Escolas, CMAEs, CMEIs, PIÁs ou outras unidades administrativas da Secretaria Municipal da Educação, mantida a mesma situação funcional. 
previdenciária $^{11}$. Como sobre o adicional de difícil provimento não incide tal contribuição, este não é incorporado aos proventos de aposentadoria. Não há elementos suficientes aqui para uma discussão sobre se tal adicional deveria ou não ser incorporado para efeitos da aposentadoria. Destaca-se, apenas, que ao avaliar os ganhos adicionais da carreira do magistério é preciso considerar a provisoriedade desse componente da remuneração.

Os critérios de recebimento da gratificação também geram questionamentos, pois uma única falta no mês faz com que os servidores percam o total do adicional, além, é claro, do desconto da falta. Esse capcioso critério faz com que os profissionais, durante os processos de mobilização por melhorias de condições de trabalho, por exemplo, acabem por resistir à idéia de adesão ao movimento, pois, além da falta anotada na ficha funcional, poderá ter uma perda financeira maior.

Entretanto, a questão posta se refere à garantia de padrões de qualidade para a escola pública. Durante os processos anuais de remanejamento, historicamente verificou-se a dificuldade de lotação de unidades que se encontram na região sul da cidade de Curitiba, ou em locais que concentram maior vulnerabilidade social, em áreas distantes do centro da cidade, nos chamados bolsões de pobreza da capital. Segundo a Secretaria de Recursos Humanos, os profissionais do magistério, em sua maioria, residem em regiões mais centrais da cidade.

Dessa forma, uma grande rotatividade de profissionais, a cada ano, é a realidade de muitas unidades. Essa rotatividade é um elemento que

11 Conforme o parecer da assessoria jurídica do Sindicato dos Servidores do Magistério Municipal de Curitiba (SISMMAC), “O montante incorporável aos proventos depende da lei incorporadora, desde que respeitados os dispositivos constitucionais e legais federais, assim como depende da regra pela qual o servidor irá se aposentar, se pela integralidade da última remuneração ou pela média aritmética. As principais normas infraconstitucionais que tratam da matéria são a Lei 9717/98, Portaria 4992/98 do Ministério da Previdência, Lei 10887/2004, Orientação Normativa 1/2007 do Ministério da Previdência. Em âmbito municipal, além das leis que criaram as vantagens e determinaram que fossem incorporáveis aos proventos, as duas principais normas que regulam a matéria são as leis 10817/ 2003 e 12207/ 2007 . É com base nestas normas que o Município optou por fazer incidir contribuição previdenciária sobre as verbas já mencionadas, além da Responsabilidade Técnica, Risco de Vida e Saúde, Adicional de Insalubridade, Risco Técnico para motoristas e taquígrafos, entre outros. Com base nas mesmas normas e outras optou por não fazer incidir contribuição previdenciária sobre outras, como é o caso da gratificação de Difícil Provimento e as demais já mencionadas. Se sobre todas estas gratificações pode incidir contribuição previdenciária, por quais razões não poderia incidir sobre a gratificação de difícil provimento criada pela lei 10190/2001 e modificada pela lei 12114/2007 Apenas a ausência da previsão na Lei Municipal justifica". 
poderá interferir negativamente na implementação do Projeto Político e Pedagógico desenvolvido nas unidades. E, nesse sentido, os adicionais de difícil provimento, enquanto fatores que incentivam a permanência dos profissionais do magistério na mesma unidade, se transformam num instrumento que pode resultar em maior qualidade para o processo ensino-aprendizagem.

A sexta gratificação encontrada nos PCCS tem relação, novamente, com o tipo de atuação do profissional: refere-se à gratificação pela atuação na educação especial. Nesse caso, os professores da REE/PR recebem um acréscimo de $50 \%$ sobre o valor correspondente ao nível e à classe em que se encontram na carreira. $\mathrm{O}$ professor precisa ser habilitado especificamente na área de Educação Especial e estar no exercício da docência ou no atendimento pedagógico especializado aos alunos com necessidades educacionais especiais.

No caso da RME/Curitiba, tal gratificação também existe e tem algumas especificações previstas no PCCS: fazem jus à gratificação de $50 \%$ sobre o vencimento básico inicial da área de atuação, pelo exercício de efetiva docência, suporte técnico pedagógico ou função diretiva em Escolas de Educação Especial, integrantes da Rede Municipal de Ensino; $30 \%$ sobre o vencimento básico inicial da área de atuação, pelo exercício de efetiva docência em classes especiais; $30 \%$ sobre o vencimento básico inicial da área de atuação, pelo exercício de efetiva docência em sala de recurso; e 30\% sobre o vencimento básico inicial da área de atuação, pelo exercício de efetiva docência, suporte técnico pedagógico ou função diretiva nos Centros Municipais de Atendimento Especializado.

O sétimo elemento de diferenciação da remuneração de professores encontrado nos PCCS refere-se à gratificação pelo cargo de diretor de estabelecimento de ensino. No caso da REE/PR, essa gratificação é de $50 \%$ do valor do vencimento do nível I, classe 1, da carreira de professor. Há também uma gratificação para os professores que ocupam funções de vice-diretores ou diretores auxiliares nos estabelecimentos. Nesse caso, o valor corresponde a $90 \%$ do percebido pelo diretor.

Na RME/Curitiba, a gratificação está prevista e corresponde a 78,13\% do vencimento do nível 1, referência 103 G, para os diretores de escolas 
de ensino fundamental; a 40\% do vencimento do nível 1, referencia 103 G, para os vice-diretores de escolas de ensino fundamental; 30\% do vencimento do nível 1, referência 103 G, para os diretores de centros municipais de educação infantil.

Nos dois casos - gratificação por atuação na educação especial e gratificação por atuação na direção dos estabelecimentos de ensino - além de compor parcelas significativas da remuneração dos profissionais, tais elementos implicam debates acerca da concepção de gestão democrática da escola, no segundo caso, e têm implicações na compreensão dos processos de inclusão dos alunos com necessidades especiais na rede regular de ensino. Tais temas não podem ser tratados aqui. Porém, demonstram que definições sobre elementos de remuneração têm alcances maiores na concepção da organização do trabalho nas unidades educativas.

Em síntese, a remuneração dos professores, nas duas redes de ensino analisadas, pode ser apresentada nos termos do QUADRO 4:

\section{QUADRO 4}

Composição da Remuneração de Professores na REE/PR e na RME/Curitiba

\begin{tabular}{l|l|l}
\hline $\begin{array}{l}\text { COMPONENTES DA } \\
\text { REMUNERAÇÃO }\end{array}$ & Paraná/Lei n. 103/2004 & $\begin{array}{l}\text { Curitiba/Lei n. } \\
\mathbf{1 0 . 1 9 0 / 2 0 0 1}\end{array}$ \\
\hline Vencimento & $\begin{array}{l}\text { Diferenciação por titulação } \\
\text { Diferenciação por progressão }\end{array}$ & $\begin{array}{l}\text { Diferenciação por titulação } \\
\text { Diferenciação por } \\
\text { crescimento horizontal }\end{array}$ \\
\hline Gratificações & $\begin{array}{l}\text { Tempo de serviço } \\
\text { Abono permanência } \\
\text { Educação Especial } \\
\text { Direção de escola }\end{array}$ & $\begin{array}{l}\text { Tempo de serviço } \\
\text { Abono permanência } \\
\text { Educação Especial } \\
\text { Direção de escola } \\
\text { Difícil provimento }\end{array}$ \\
\hline Adicionais & Adicional noturno & $\begin{array}{l}\text { Adicional Noturno } \\
\text { (previsto) }\end{array}$ \\
\hline Auxílios & Auxílio transporte & $\begin{array}{l}\text { Auxílio transporte } \\
\text { (conforme teto salarial) }\end{array}$ \\
\hline
\end{tabular}

Fonte: PARANÁ (2004); CURITIBA (2001). 


\section{Considerações finais}

Uma avaliação geral dos dois Planos de Carreira, aqui apresentados, permite algumas conclusões preliminares. Parece haver um atendimento geral das grandes orientações das DNC que têm relação com temas recorrentes no debate sobre a valorização do magistério. Assim, nos dois casos, encontramos valorização da titulação, mecanismos de valorização da formação continuada e valorização do tempo de serviço. Por outro lado, a questão da remuneração docente parece ser ainda fortemente definida por critérios orçamentários. Assim, especialmente no caso de Curitiba, a necessidade de procedimentos seletivos que dependem de previsão orçamentária para os avanços funcionais dos professores evidencia tal relação. No caso da rede estadual do Paraná, ainda que a maior parte da carreira propicie avanços automáticos à medida que os professores alcançam os critérios estabelecidos, pode-se problematizar até que ponto a manutenção de mais de um terço dos professores em contratos precários não é uma medida de contenção de despesas com os direitos dos trabalhadores.

Outra dimensão que pareceu evidente foi a necessidade de se compreender, para além das regras gerais de definição dos vencimentos, as regras de composição das remunerações que implicam gratificações, abonos ou auxílios. Tais elementos, além de potencialmente resultarem em ganhos salariais, podem ter implicações na concepção de escola, especialmente nos casos em que as gratificações são resultado de medidas de valorização das funções de direção, valorização de certas modalidades de ensino ou enfrentamento de dificuldades de lotação das escolas.

Parece, portanto, que a compreensão de casos específicos de planos de carreira, em execução nas unidades federativas, pode contribuir para que saibamos um pouco mais sobre o que efetivamente têm sido as condições de trabalho dos professores brasileiros e se as políticas propostas no âmbito nacional estão além ou aquém das realidades locais. 


\section{Referências}

ANUATTI, et al. Avaliação dos Salários dos Professores da Rede Pública de Ensino Fundamental em Tempos de FUNDEF. Revista de Economia Aplicada, São Paulo, v. 8, p. 414-437, 2004.

BALZANO, S. Estudo dos planos de carreira e remuneração do magistério da educação dos estados brasileiros. Consed - GT valorização do Magistério, 2005.

BARROS, R. P. et al. O mercado de trabalho para professores no Brasil. In: ENCONTRO NACIONAL DE ECONOMIA, XXIX, 2001, Salvador. Anais ... Salvador: Associação Nacional dos Centros de Pós-Graduação em Economia, 2001.

BECKER, K. A remuneração do trabalho do professor no ensino fundamental público brasileiro. 2008. Dissertação (Mestrado) - Universidade de São Paulo, São Paulo.

BRASIL. Constituição (1988). Constituição da República Federativa do Brasil, 1988. Disponível em <http:/ / www.planalto.gov.br>. Acesso em: 05 out. 2010.

Congresso Nacional. Lei n. 9.394 de 20 de dezembro de 1996. Estabelece as diretrizes e bases da educação nacional. Diário Oficial da República Federativa do Brasil. Brasília, v. 135, n. 248, 1996 .

Congresso Nacional. Lei n. 9.424 de 24 de dezembro de 1996. Dispõe sobre o Fundo de Manutenção e Desenvolvimento do Ensino Fundamental e de Valorização do Magistério. Diário Oficial da República Federativa do Brasil. Brasília: 1996b.

Congresso Nacional. Emenda Constitucional n. 41 de 19 de dezembro de 2003. Modifica os arts. 37, 40, 42, 48, 96, 149 e 201 
da Constituição Federal, revoga o inciso IX do § 3 do art. 142 da Constituição Federal e dispositivos da Emenda Constitucional n ${ }^{\circ} 20$, de 15 de dezembro de 1998, e dá outras providências. Disponível em: <http://www.planalto.gov.br/ccivil_03/Constituicao/Emendas/ Emc/emc41.htm>. Acesso em: 05 out. 2010.

. Congresso Nacional. Emenda Constitucional n. 53 de 19 de dezembro de 2006. Dá nova redação aos arts. $7^{\circ}$, 23, 30, 206, 208, 211 e 212 da Constituição Federal e ao art. 60 do Ato das Disposições Constitucionais Transitórias. Disponível em: <http://www.planalto. gov.br/ccivil_03/constituicao/Emendas/Emc/emc53.htm>. Acesso em: 05 out. 2010.

. Congresso Nacional. Lei n. 11.494 de 20 de julho de 2007. Regulamenta o Fundo de Manutenção e Desenvolvimento da Educação Básica e de Valorização dos Profissionais da Educação - FUNDEB, de que trata o art. 60 do Ato das Disposições Constitucionais Transitórias; altera a Lei no 10.195, de 14 de fevereiro de 2001; revoga dispositivos das Leis nos 9.424, de 24 de dezembro de 1996, 10.880, de 9 de junho de 2004, e 10.845, de 5 de março de 2004; e dá outras providências.. Diário Oficial da República Federativa do Brasil. Brasília: 2007.

Conselho Nacional de Educação. Resolução n. 02 de 28 de maio de 2009. Fixa as Diretrizes Nacionais para os Planos de Carreira e Remuneração dos Profissionais do Magistério da Educação Básica Pública, em conformidade com o artigo $6^{\circ}$ da Lei $\mathrm{n}^{\circ} 11.738$, de 16 de julho de 2008, e com base nos artigos 206 e 211 da Constituição Federal, nos artigos $8^{\circ}, \S 1^{\circ}$, e 67 da Lei $n^{\circ} 9.394$, de 20 de dezembro de 1996, e no artigo 40 da Lei no 11.494, de 20 de junho de 2007. Disponível em: <http:/ / portal.mec.gov.br/dmdocuments/resolucao_ cne_ceb 002_2009.pdf>. Acesso em: 05 out. 2010.

CASTRO, Jorge Abrahão de. Fundo de Manutenção e desenvolvimento do 
Ensino e Valorização do Magistério (Fundef) e seu impacto no financiamento do ensino fundamental. Brasília: IPEA, 1998.

CURITIBA. Lei n. 6.761 de 08 de novembro de 1985. Dispõe sobre o Estatuto do Magistério Público Municipal. Disponível em: < http:/ / www.leismunicipais.com.br/cgi-local/form_vig.pl>. Acesso em 16 de out. 2010.

CURITIBA. Lei n. 8.248 de 09 de setembro de 1993. Dispõe sobre a aplicação da gratificação pelo regime integral de trabalho aos ocupantes de carreiras de professor, supervisor escolar e orientador educacional. Disponível em: < http:/ / www.leismunicipais.com.br/ cgi-local/form_vig.pl>. Acesso em 16 de out. 2010.

CURITIBA. Lei n. 10.190 de 28 de junho de 2001. Institui o Plano de Carreira do Magistério Público Municipal. Disponível em: < http:/ / www.jusbrasil.com.br/legislacao/722452/lei-10190-01-curitiba-0>. Acesso em 16 de out. 2010.

DAVIES, N. O Fundefe as verbas da educação. São Paulo: Xamã, 2001.

MORDUCHOWICZ, A. Carreira, incentivos e estruturas salariais docentes. PREAL/BRASIL, 2003.

PARANÁ. Lei Complementar n. 103 de 15 de março de 2004. Institui e dispõe sobre o Plano de Carreira do Professor da Rede Estadual de Educação Básica do Paraná e adota outras providências. Disponível em: < http:/ / celepar7cta.pr.gov.br/SEEG/sumulas.nsf/319b106715f6 9a4b03256efc00601826/0136dea4d1af589c03256e98006e2e8b?OpenDoc ument>. Acesso em: 12 out. 2010...

PARANÁ. Lei Complementar n. 108 de 18 de maio de 2005. Dispõe sobre a contratação de pessoal por tempo determinado, para atender a necessidade temporária de excepcional interesse público, nos órgãos 
da Administração Direta e Autárquica do Poder Executivo, conforme especifica. Disponível em: < http:/ / celepar7cta.pr.gov.br/seap/ legrh-v1.nsf/5199c876c8f027f603256ac5004b67da/c58a49f6c28c0cd583 257014004a4653?OpenDocument>. Acesso em: 12 out. 2010...

PARANÁ. Decreto n.7.558 de 28 de junho de 2010. Publica as tabelas de vencimento básico e de remuneração com índice geral de 5\%, concedido às carreiras estatutárias do Poder Executivo pela Lei $\mathrm{n}^{\circ}$ 16.468, de 2010. Disponível em: < http:/ / celepar7cta.pr.gov.br/ SEEG/sumulas.nsf/2b08298abff0cc7c83257501006766d4/c0bfa 5be932ecf6b83257757004df836?OpenDocument>. Acesso em: 12 out. $2010 \ldots$

PARANÁ. Secretaria de Estado da Educação. Sistema de Administração da Educação. SEED em Números. Paraná, 2010. Disponível em: < http://www.educacao.pr.gov.br/modules/ conteudo/conteudo.php?conteudo=55>. Acesso em: 05 out. 2010.

PINTO, J. M. R. Remuneração adequada do professor: desafio à educação brasileira. Revista Retratos da Escola, Brasília: CNTE, v. 3, n. 4, p.51-69, jan-jun/2009.

TORRECILLA, F. Javier Murillo (coord. Académico). Modelos Innovadores en la Formación Inicial Docente: uma apuesta por el cambio. Estudio de casos de modelos innovadores en la formación docente en la América Latina y Europa. Santiago: OREALC/UNESCO. Junio, 2006. Disponível em: <http:www.unesco.cl>. Acesso em: 05 out. 2010. 


\title{
Career plans of state education network and network Paraná hall of teaching Curitiba: one year comparison
}

\begin{abstract}
Understanding the implications of the new $\mathrm{DCN}$ for the work conditions and appreciation of teachers requires a knowledge of local dynamics of career rules, because many states and municipalities approved careers in the previous periods, which certainly have specific identities. These careers show proximity and incompatibilities to the recent national law. So, the proposal of this article is to compare two operating careers in the Paraná State: one in the Curitiba Municipal Education System and, the other one, in the Paraná State Education System. The first one was approved in 2001 and the second one was approved in 2004. We have analyzed the elements that define the kind of admission/entrance in the career, ways of promotion / evolution and complementary components of the salary. The analysis has shown certain guarantees of quality of teachers' careers even though there still are limits for budget conditions in the Education Systems.
\end{abstract}

Keywords: Teaching. Career. Remuneration

Recebido: 18/01/2012

Aprovado: 14/06/2012 